\title{
高职院校学前教育专业男女生比例失衡成因及对策研究一以武汉 城市职业学院为例
}

\author{
吴雅辛 \\ 武汉城市职业学院 \\ DOI:10.32629/er.v3i3.2545
}

[摘 要] 本文采用文献资料法、访谈法、问卷调查和统计分析等方法,对高职院校学前教育专业学生性别比例失衡问题进行系统的研究,重点 探讨这种失衡给教育和社会带来的影响,分析学前教育专业男女生比例失衡的深层原因,并提出相应对策,促进学前教育专业及幼儿教育更好的 发展。

[关键词] 高职; 学前教育; 男女比例；失衡；对策

\section{前言}

在国际竞争日益激烈的今天, 教育水平的高低是衡量国家综合竞争力 强弱的重要标准之一。因此提高教育质量势在必行。而对于保证教育质量 而言, 教师无疑是最重要的。而高质量的幼儿教师队伍离不开高质量的学 前教育专业学生源。高职院校学前教育专业学生是未来幼儿教师的主力军, 这些学前教育专业学生的质量和结构很大程度上决定了未来幼儿教育中 教师的质量和结构。

人们常用“阴盛阳衰”来形容学前教育专业男女生比例失衡这一现象, 但为什么会出现这种失衡以及会产生哪些不利影响呢? 本文通过对武汉城 市职业学院学前教育专业男女生比例现状的调查, 分析高职院校学前教育 专业男女生比例失衡的原因以及造成的影响, 最后提出建议和对策。

\section{1 研究对象与方法}

1. 1 研究对象

高职院校学前教育专业学生。

1.2研究方法

1.2.1文献研究法

根据研究的内容需要查阅并收集国内外相关领域的书籍、报刊、杂志 以及网上资料, 收集了有关我国学前教育专业男女比例失衡的论文及文献 等相关文献, 为本研究打下基础。

\subsection{2访谈法}

就研究的有关问题对学前教育、教育学方面的专家、教授进行访谈, 获取他们的意见和建议, 为本研究的顺利进行提供依据。

\subsection{3 问卷调查法}

依据调查的目的, 遵循问卷设计的基本要求, 制作了问卷调查表, 并对 问卷的信度和效度进行检验。对武汉城市职业学院非学前教育专业男生随 机发放调查问卷, 共发出 500 份问卷, 回收 473 份, 回收率为 $94.6 \%$

\subsection{4 统计分析法}

对比所发放的问卷, 并运用Microsoft Excel对所收集的原始数据进 行整理、分类, 然后用 SPSS统计软件进行统计, 对收集、访谈、问卷所获 得的资料进行分析, 最后得出结论。

\section{2 研究结果与分析}

2. 1武汉城市职业学院学前教育专业男女生比例现状

表1所显示的是武汉城市职业学院学前教育专业在校男女生人数情 况。2017级、2018级、2019级和五年一贯制男生所占比例分别是：2.23\%、 $1.92 \%$ 、2. 96\%和 $4.35 \%$, 男生总体占比仅有 $2.74 \%$, 显而易见男生所占比重极 低, 呈现严重的不协调。 表1＼cjkstart武汉城市职业学院学前教育专业男女生比例统计表

\begin{tabular}{|c|c|c|c|}
\hline 年级 & 总人数 & 男生人数 & $\begin{array}{c}\text { 男生所占比例 } \\
(\%)\end{array}$ \\
\hline 2017 级 & 943 & 21 & 2.23 \\
\hline 2018 级 & 728 & 14 & 1.92 \\
\hline 2019 级 & 846 & 25 & 2.96 \\
\hline 五年一贯制 & 552 & 24 & 4.35 \\
\hline 合计 & 3069 & 84 & 2.74 \\
\hline \multicolumn{4}{|r|}{}
\end{tabular}

表1数据显示, 幼儿教育的职前教师---学前教育专业男女生比例已严 重失衡, 势必在很大程度上影响幼儿教师队伍的男女比例构成, 影响幼儿 教育健康有序的发展。

2.2 高职院校学前教育专业男女生比例失衡的原因

由表 2 可知, 男生不愿选择学前教育专业受多重因素的影响, 其中幼儿 教师社会地位偏低 (63.11\%), 幼儿教师工资待遇不高 $(62.60 \%)$, 幼儿教师 发展空间有限 (58.21\%) 以及对幼儿教师职业认同感普遍较低 (65.14\%) 等 是男生不愿选择学前教育专业的主要原因。

表2 男生不愿选择学前教育专业原因统计表

\begin{tabular}{|c|c|}
\hline 原因 & 百分比 (\%) \\
\hline 幼儿教师社会地位偏低 (社会认知偏差) & 63.11 \\
\hline 幼儿教师工资待遇不高 & 62.60 \\
\hline 幼儿教师发展空间有限 & 58.21 \\
\hline 对幼儿教师职业认同感普遍较低 & 65.14 \\
\hline 传统观念影响 & 43.29 \\
\hline 男女性格差异 & 38.26 \\
\hline 幼儿家长不信任 & 34.57 \\
\hline 父母不支持 & 17.96 \\
\hline 师范专业政策优势弱化 & 28.73 \\
\hline 基础教育中教师的性别失衡影响 & 20.13 \\
\hline 高中教师填报志愿影响 & 9.76 \\
\hline 其他 & 8.37 \\
\hline
\end{tabular}

2.2.1幼儿教师的社会地位偏低

大众认为, 我国教育系统中社会地位排名: 大学教师>中小学教师〉幼 儿教师, 而女幼师的社会地位又高于男幼师, 男幼师的社会地位处于教育 系统的最底端。幼儿教师社会地位不高直接降低了幼儿教师的职业吸引力, 导致教育人才的不足, 尤其是男教师的稀缺和流失。

2.2.2幼儿教师的工资待遇不高

我国自古以来素有尊师重教的优良传统, 在现代社会, 教师被认为是 人类灵魂的工程师。幼儿教师肩负着培养祖国未来花朵的使命, 是高尚的 职业, 同时也承担着繁重的工作任务和压力。劳动报酬高低应取决于劳动 所创造价值的多少, 幼儿教师理应获得更多的报酬, 而目前我国幼儿教师 
的工资水平整体不高。因此工资待遇不高成为男生不愿就读学前教育专业 的主要原因之一。

\subsection{3幼儿教师的发展空间有限}

在社会快速发展的今天, 幼儿教师只有经常到 “外面的世界” 开拓眼 界, 才能寻求自身更好的发展, 从而扩大发展空间。而现在多数幼儿园要求 教师以牧羊人的身份 “看护” 学生, 而这些都无需更为专业的知识辅助, 这就导致幼儿教师往往会因工作任务重、压力大等原因, 无法使自身的专 业技能和科研能力等方面得到提升, 教师的专业发展受到了很大程度的限 制, 从而降低了幼儿教师职业吸引力。

\subsection{4男性对幼儿教师职业认同感普遍较低}

受传统观念的影响, 绝大多数男性认为, 照顾婴幼儿是女人的职业, 只有女性可以胜任, 男性做幼儿教师有损尊严。男幼师的自我认同是围 绕自我所展开的认同, 强调的是男幼师自我的心理与生理体验。男幼师 都有自己的交际圈, 人们总是不自觉地拿自己和他人比较, 当发现和自 己不相上下的人甚至不如自己的人却拥有更好的物质生活条件、成就地 位时, 会产生嫉妒、不安和挫败感。因此, 他们对幼儿教师职业的认同感 处于较低水平。

2.3 高职院校学前教育专业男女生比例失衡造成的问题

2. 3. 1 不利于教学活动的组织与开展

目前高职院校学前教育专业, 由于男女比例失衡严重, 给教学活动的 组织与开展带来了很大的挑战。由于性别的差异, 男女学生在性格、思维 等方面都有着明显的不同。女生比较乘巧、细心, 擅长具体形象思维, 偏爱 纪律性强、环境稳定的教学活动。而男生表现更为主动, 擅长抽象逻辑思 维, 偏爱实践性较强、多样化的教学活动。他们优势互补、互相提高, 对于 营造互补性的学习课堂十分有益。而如果男女生比例失衡, 则不利于教学 活动的组织与开展, 势必影响教学活动的整体效果。

2.3.2不利于学生的个性成长和完善

从学生个性发展来看, 男女比例差异过大, 会对学生的个性成长和完 善造成不利影响。男女比例差异过大, 使得男生成为 “边缘人”。男生阳刚 之气在这种环境中无法得到培养, 他们甚至可能沾染上部分女生的 “公主 病”, 害怕困难, 在学习中难以主动去参与竞争和创造, 长此以往, 对于他们 将来进入社会中的性别和工作角色塑造都会产生较大的危害。

\section{3. 3 导致幼儿教师性别比例失衡成为必然}

学前教育专业以培养优秀的幼儿教师为目标, 为我国幼儿教育输送师 资。高职院校学前教育专业学生是未来幼儿教师的主力军, 这些学前教育 专业学生的质量和结构很大程度上决定了未来幼儿教育中教师的质量和 结构。那么, 学前教育专业学生整体的男女比例失衡必然会导致幼儿教师 队伍性别比例的失衡。幼儿教育的发展与幼师队伍的质量和结构紧密相关, 而性别比例构成便是一个重要因素, 因此幼儿教师性别比例不平衡所带来 的负面影响不容忽视。

\section{3 结论与建议}

3. 1 结论

高职院校学前教育专业男女生比例呈现严重的失衡。导致失衡的主要 原因有幼儿教师的社会地位偏低、工资待遇不高、发展空间有限、男性对 幼儿教师职业认同感较低。由此对教学活动的组织与开展、学生的个性成 长和完善、幼儿教师性别比例都带来不利影响。

3. 2 建议

3.2.1重塑社会认知
需要重塑幼儿教师的社会认同度。公众认为幼儿教师只是看护孩子的 “阿姨”, 尤其轻视男幼师的想法应该利用媒体给予正确的引导, 让公众认 识到男幼师在学生成长过程中有着举足轻重的作用, 并需引起高度重视。 因此, 加强对幼师工作重要性的认识是十分重要的。国务院2018年发布了 的《关于学前教育深化改革规范发展的若干意见》指出: “学前教育是终 身学习的开端, 是国民教育体系的重要组成部分, 是重要的社会公益事 业。”从国家如此重视学前教育可知, 幼师职业将来会具有更高的社会地位, 这将吸引更多的男生主动投身于幼师行列。

3.2.2提高幼儿教师的工资待遇

虽然国家、社会一直提倡男女平等, 但现阶段男性在经济方面的压力 明显比女性高, 是因为男性仍承担家庭的大部分开支。因此吸引男生报考 学前教育专业的一个有效方式是提高幼师的工资待遇。与其他行业相比, 从事幼师工作的工资较少, 而且不同地区、不同办园性质的工资待遇相差 较大。因此提高幼师的工资待遇可以吸引更多男生报考学前教育专业, 从 而有效缓解高职院校学前教育专业男女生比例失衡的问题。

3.2.3为男幼师创造更多的发展空间

男幼师和女幼师相比, 具有更高的成就欲望, 他们渴望更快地得到成 长, 渴望得到提拔、受到重用。而不管是外出培训, 还是提拔升迁, 女幼师 明显得到的比男幼师要多得多。因此幼儿园领导者要转变观念, 改进激励 机制。为抑制男幼师的减少和缺失, 幼儿园应该建立健全针对男幼师这一 特殊群体的评价体系和奖励措施, 评价教师幼师工作要考虑性别的差异, 不能用机械教条的标准来评价男幼师。同时, 除了设法加强男幼师的专业 培训外, 更重要的是幼儿园应该为男幼师创造更多的发展空间。

3.2.4加强宣传教育, 激发男性对幼师职业的认可度

解决高职院校学前教育专业男女比例失衡的问题, 最重要的是消除传 统观念, 不能固化职业 “性别”。以从古到今优秀的男性教育家为示范, 打 破 “教育是适合女性的最佳职业” 这一传统观念, 使得男性积极投身于幼 儿教育事业, 对幼师职业有清醒的认识并产生高度的责任感。只有学校的 男女幼师比例协调, 才能给孩子创造一个完整的校园世界。想要更多的男 生选择学前教育专业, 就需要实现男生对幼师的认可, 努力完善好技能, 实 现自身的人生价值和社会价值。

[参考文献]

[1]国务院.关于学前教育深化改革规范发展的若千意见[Z].2018.

[2]赫尔格森.性别心理学(第二版)[M].世界图书,2005.

[3] 张海钟. 高校学生性别比例问题综述 [J]. 理工高 教,2009,28(1):16-18.

[4]王俊.教师职业的性别标识探论一兼谈师范类院校男女生比例失衡 问题[J].高等教育研究,2015,36(6):65-72.

[5]王小波.大学男女比例失衡_表象背后隐藏的危机[J].现代阅 读,2012,(15):10-11.

[6]邓招梅.师范院校男女比例失衡对男生心理发展的影响研究[J].健 康教育,2013,(12):256-258.

作者简介:

吴雅辛(1991--), 女, 汉族, 湖北襄阳人, 教师/助教, 硕士研究生, 研 究方向: 体育教学、学生管理。

基金项目:

武汉城市职业学院2019年校级青年教师专项课题(2019whcvcQ13)。 